\title{
A educação profissional e tecnológica nos Institutos Federais: Uma análise histórica a
}

\section{luz de Paulo Freire}

\author{
Professional and Technological Education in Federal Institutes: A historical analysis in the light of \\ Paulo Freire \\ La Educación Profesional y Tecnológica em los Institutos Federales: Un análisis histórico a la luz \\ de Paulo Freire
}

Recebido: 27/06/2021 | Revisado: 19/07/2021 | Aceito: 30/07/2021 | Publicado: 05/08/2021

Âmara Fuccio de Fraga e Silva
ORCID: https://orcid.org/0000-0002-4869-4641
E-mail: amara.fuccio@ifmg.edu.br
Deyse Almeida dos Reis
Instituto Federal de Educação, Ciência e Tecnogia de Minas Gerais, Brasil
ORCID: https://orcid.org/0000-0002-6627-1247
E-mail: deysereis.reis@gmail.com

\begin{abstract}
Resumo
Este artigo tem como objetivo descrever o desenvolvimento da Educação Profissional e Tecnológica ao longo dos séculos XX e XXI, acompanhando as mudanças nas concepções vigentes de trabalho e da sociedade, bem como a adequação dessa modalidade de ensino às novas bases pedagógicas, as quais priorizam a educação formadora da autonomia do aluno. Para tanto, foram relacionados os marcos legais referentes à instituição da Educação Profissional e Tecnológica com as transformações socioeconômicas ao longo do século XX, bem como foi observada a contribuição da pedagogia crítica de Paulo Freire na concepção vigente do ensino técnico profissionalizante.
\end{abstract}

Palavras-chave: Educação profissional e tecnológica; Institutos federais; Pedagogia crítica; Paulo Freire.

\begin{abstract}
This article aims to describe the development of Professional and Technological Education throughout the 20th and 21 st centuries, following the changes in current conceptions of work and society, as well as the adequacy of this teaching modality to the new pedagogical bases, which prioritize the education that forms the autonomy of the student. Therefore, the legal frameworks associated with the institution of Professional and Technological Education were related to the socioeconomic transformations throughout the 20th century, as well as the contribution of Paulo Freire's critical pedagogy in the current conception of professionalizing technical education was observed.
\end{abstract}

Keywords: Professional and technological education; Federal institutes; Critical pedagogy; Paulo Freire.

\section{Resumen}

Este artículo tiene como objetivo describir el desarrollo de la Educación Profesional y Tecnológica a lo largo de los siglos XX y XXI, siguiendo los cambios en las concepciones actuales del trabajo y de la sociedad, así como la adecuación de esta modalidad docente a las nuevas bases pedagógicas, que priorizan la formación de la autonomía del alumno. Para eso, los marcos legales relativos a la institución de la Educación Profesional y Tecnológica se relacionaron con las transformaciones socioeconómicas a lo largo del siglo XX, así como se observó el aporte de la pedagogía crítica de Paulo Freire en la concepción actual de la educación técnica y profesional.

Palabras clave: Educación profesional y tecnológica; Institutos federales; Pedagogía crítica; Paulo Freire.

\section{Introdução}

No início do século XXI, a oferta de Educação Profissional e Tecnológica (EPT) passou por uma expansão sem precedentes, a partir da criação de trinta e oito Institutos Federais de Educação, Ciência e Tecnologia distribuídos pelo território nacional. Essa nova organização educacional possibilitou a capilaridade do ensino técnico, democratizando o ensino público e gratuito e aproveitando os arranjos produtivos locais. 
O Artigo 205 da Constituição Federal de 1988 assegura que a "educação, direito de todos e dever do Estado e da família, será promovida e incentivada com a colaboração da sociedade, visando ao pleno desenvolvimento da pessoa, seu preparo para o exercício da cidadania e sua qualificação para o trabalho". Esse documento, presente na Carta Magna brasileira e base da fundamentação das políticas educacionais do país, reforça a necessidade de ação conjunta com o objetivo de articular três aspectos fundamentais: desenvolvimento individual, prática cidadã e qualificação profissional.

Nesse sentido, a Educação Profissional e Tecnológica (EPT), prevista pela Lei de Diretrizes e Bases da Educação Nacional, emerge como alternativa para a efetivação desse tripé, uma vez que, ao abranger cursos de qualificação, habilitação técnica e tecnológica, contribui para a inserção e para a atuação do jovem no mercado de trabalho e na vida em sociedade.

Assim, o presente trabalho tem por objetivo analisar o desenvolvimento da Educação Profissional e Tecnológica no Brasil, bem como a criação dos Institutos Federais sob a ótica freireana. Ao longo do século XX, observa-se a influência do contexto histórico na orientação das diretrizes educacionais do ensino técnico, de modo a acompanhar os movimentos socioeconômicos de cada época. Além disso, destaca-se a contribuição da teoria da pedagogia crítica na instituição das atuais bases da Lei de Diretrizes e Bases da Educação Nacional (LDB).

Esse artigo está organizado em duas partes. A primeira se propõe a descrever o percurso da Educação Profissional Tecnológica no Brasil, de acordo com as transformações socioeconômicas. Já a segunda parte evidencia a influência das bases educacionais defendidas por Paulo Freire na criação das diretrizes dos Institutos Federais.

\section{Metodologia}

A presente pesquisa adota a metodologia qualitativa, que, segundo Ludke e André (1986), utiliza a observação direta como principal técnica de investigação. Nesse método, o pesquisador possui um grau de participação no trabalho ao selecionar, organizar e interpretar as informações coletadas, aproximando o observador da perspectiva do sujeito na situação estudada.

Dessa forma, a partir da definição do tema da pesquisa, foi utilizada a técnica de análise documental, identificando-se as principais referências bibliográficas do assunto. Para Philips (1974, p.187), define-se documentos como "quaisquer materiais escritos que possam ser usados como fonte de informação sobre o comportamento humano". Nesse sentido, dentre os possíveis documentos, pontua-se que, de acordo com Ludke e André (1986, p.38), "estes incluem desde leis e regulamentos, normas, pareceres, cartas, memorandos, diários pessoais, autobiografias, jornais, revistas, discursos, roteiros de programas de rádio e televisão até livros, estatísticas e arquivos escolares".

Assim, em um primeiro momento, buscou-se aporte na legislação brasileira para evidenciar que a promoção da Educação Profissional e Tecnológica não é um fenômeno recente, mas que possui incentivo público há mais de um século, de modo a acompanhar as necessidades do mercado de trabalho. Com base em uma análise histórica, foram relacionados os marcos legais referentes à instituição da Educação Profissional e Tecnológica com as transformações socioeconômicas ao longo do século XX.

Cronologicamente, até meados do século XX, os primeiros documentos legais refletem a necessidade de capacitação técnica da população para atender as demandas do incipiente mercado industrial do país. Acompanhando a constituição de uma sociedade salarial no Brasil plenamente inserida no contexto capitalista, houve uma reorientação do modelo das escolas técnicas, as quais se voltaram para a oferta de uma melhor e mais ampla qualificação profissional, a partir da criação e difusão dos CEFETs, conforme leis publicadas após a década de 70. Por fim, com a publicação da Lei de Diretrizes e Bases da Educação Nacional de 1996 e com a lei de criação dos Institutos Federais em 2008, observou-se a necessidade de formação de indivíduos mais capacitados para se adaptarem, de forma ativa e autônoma, frente às transformações trabalhistas e tecnológicas.

Em um segundo momento, com base na leitura de artigos e de livros ligados ao tema, foi observado que a criação dos Institutos Federais em 2008 teve influência das bases educacionais preconizadas pelo pedagogo Paulo Freire. Nesse sentido, foi 
destacada a contribuição do educador com as obras "Educação e Mudança" (1979), "Pedagogia do Oprimido" (1987) e "Política e Educação" (2001), na nova concepção de educação técnica profissionalizante.

\section{Resultados e Discussão}

\subsection{Breve resgate histórico da Educação Profissional e Tecnológica (EPT)}

Atualmente, a EPT prevê o desenvolvimento das dimensões do trabalho, da ciência e da tecnologia. Mesmo em estágios anteriores da história brasileira, já existia a preocupação com a educação profissional do Brasil. Sob análise legal, a instituição dessa modalidade educacional ocorreu em 1909, a partir da assinatura do Decreto $\mathrm{n}^{\circ} 7.566$, com a criação das primeiras dezenove "Escolas de Aprendizes e Artífices”. Em 1937, pela primeira vez, a Constituição Federal promulgada por Getúlio Vargas transformou essas instituições em liceus industriais. Nesse momento histórico, cabe ressaltar a construção da visão, muitas vezes, pejorativa acerca do trabalho e do público-alvo dessas escolas.

É possível observar que o projeto inicial das escolas técnicas era direcionado aos membros de classes populares, uma vez que, sob a memória do passado escravista, o trabalho manual persistia sendo desvalorizado.

Sob a perspectiva de Freire,

A sociedade fechada se caracteriza pela conservação do status ou privilégio e por desenvolver todo um sistema educacional para manter esse status. Estas sociedades não são tecnológicas, são servis. Há uma dicotomia entre o trabalho manual e o intelectual. Nestas sociedades nenhum pai gostaria que seus filhos fossem mecânicos se pudessem ser médicos, mesmo que tivessem vocação de mecânicos. Consideram o trabalho manual degradante; os intelectuais são dignos e os que trabalham com as mãos são indignos. Por isso as escolas técnicas se enchem de filhos das classes populares e não das elites (Freire, 1979, p.18).

Nesse sentido, enquanto o trabalho intelectual das universidades era reservado aos membros da elite, o ensino profissionalizante deveria se voltar para a constituição de uma mão de obra qualificada para atender as pretensões econômicas da incipiente indústria nacional.

De acordo com Kunze,

No âmbito da educação profissional, recaiu sobre as escolas da rede federal a incumbência de difundir, em especial, a essa clientela, os valores e preceitos do novo regime governamental, os hábitos do trabalho e da obediência às regras e uma formação profissional, uma profissão, um ofício, que a transformasse em operários frutíferos à nação, trabalhadores ordeiros e qualificados para atuarem nas futuras indústrias brasileiras (Kunze, 2009, p.22).

Sendo assim, foi necessário o incremento da oferta da Educação Profissional e Tecnológica. Nesse contexto, o panorama da EPT foi alterado, inicialmente, pela instituição das escolas técnicas federais em 1959, as quais, a partir de 1978, foram substituídas pelos CEFET (Centro Federal de Educação Tecnológica).

Cabe salientar a transformação da visão do trabalho no Brasil ao longo do século XX. Inicialmente, pontua-se a passagem de Karl Marx que afirma que o trabalho possui uma dimensão ontológica do ser humano.

O trabalho, como criador de valores de uso, como trabalho útil, é indispensável à existência do homem - quaisquer que sejam as formas de sociedade - é necessidade natural e tema de efetivar o intercâmbio material entre o homem e a natureza, e, portanto, de manter a vida humana (Marx, 1982, p.50).

Essa passagem de Marx, inserida no século XIX em um contexto de desenvolvimento do capitalismo alemão e da instituição de uma sociedade salarial, a partir da dualidade burguesia-proletariado, não pode ser compreendida no mesmo momento no panorama brasileiro, uma vez que ainda possuíamos uma sociedade escravocrata, marcada pela "objetificação" do 
escravizado. Nesse período, o trabalho manual era visto de forma depreciativa e restrito às classes populares, o que dificultava a valorização do trabalho como inerente à natureza humana.

Mesmo após a abolição da escravidão com a Lei Áurea (1888) e o fim do Império brasileiro (1889), a mentalidade depreciativa frente à produção manual persistiu nas primeiras décadas da república brasileira, influenciadas pelos três séculos do regime escravista. Nesse sentido, apenas com a ascensão de uma burguesia industrial no Brasil ao longo do século XX e com a possibilidade de o trabalhador livre vender sua força de trabalho, foi instituída uma sociedade salarial no país, de forma que a teoria de Marx pudesse ser aplicada.

Nesse momento, segundo Castel (1997), a maior parte dos indivíduos tem a sua inserção na sociedade mediada pelo local que ocupa na escala salarial, fruto de seu trabalho. Dessa maneira, de acordo Thompson (1981), o trabalho assume ligação “à experiência humana e à cultura”, tornando-se ferramenta indissociável à satisfação das necessidades biológicas, sociais e culturais humanas, o que reafirma, consequentemente, a sua dimensão ontológica.

Sob esse viés, mediante à possibilidade de ascensão social e de satisfação pessoal decorrentes do vínculo empregatício, houve uma mudança na visão frente ao trabalho no Brasil. Como resultado, foi intensificada a procura de grande parte da população pela melhora na qualificação profissional, de forma que os cursos de Educação Profissional e Tecnológica emergiram como possíveis alternativas para aqueles que almejam a profissionalização. Tal mentalidade impulsionou a procura por instituições que ofertarem a EPT, possibilitando a maior valorização dessa modalidade de ensino.

Com a ascensão do modelo econômico neoliberal na década de 90 em contraposição ao modelo desenvolvimentista, houve o aumento da pressão do empresariado nacional sobre o poder público por melhorias na educação básica e pela incorporação de orientações voltadas para a formação técnico-profissional dos estudantes. Tal iniciativa visava resolver o problema de qualificação da mão de obra brasileira, desenvolvendo trabalhadores capazes de inovarem e de se adaptarem frente às novas realidades econômicas e trabalhistas.

Segundo Marisa Nogueira Ramos,

Enquanto vigorou o projeto nacional-desenvolvimentista e a certeza do pleno emprego, preparar para o mercado de trabalho foi realmente a principal finalidade da educação brasileira, ainda que o acesso ao ensino superior fosse facultativo e altamente demandado. Com a crise dos empregos e mediante um novo padrão de sociabilidade capitalista, caracterizado pela desregulamentação da economia e pela flexibilização das relações e dos direitos sociais, a possibilidade de desenvolvimento de projetos pessoais integrados a um projeto de nação e de sociedade tornou-se significativamente frágil (Ramos, 2014, p.115).

Ademais, sob olhar da classe dos trabalhadores, foi difundida a ideologia da empregabilidade, a qual afirma que, quanto maior for a capacitação do trabalhador, maiores as suas chances de ingressar competitivamente no mercado de trabalho e de almejar a possibilidade de ascensão socioeconômica.

Acompanhando as transformações socioeconômicas no final do século XX, foi-se necessário o incremento da oferta da Educação Profissional e Tecnológica. Esse crescimento se deu, inicialmente, com a assinatura da Lei no 8.948/1994, que transformou as antigas escolas técnicas federais em CEFET (Centro Federal de Educação Tecnológica), os quais foram difundidos pelo território nacional.

Por fim, em 2008, a partir da Lei n. ${ }^{\circ}$ 11.892/2008, foram criados os Institutos Federais de Educação, Ciência e Tecnologia, que são instituições pluricurriculares e multicampi, voltados para a oferta de Educação Profissional e Tecnológica em todos os seus níveis. Tanto o estabelecimento dos CEFET quanto dos Institutos Federais contribuiu, de forma significativa, para a ampliação da oferta de ensino público, gratuito e democrático, articulando trabalho, ciência e cultura, com objetivo de efetivar uma formação transversal, ligada não apenas à capacitação para ofícios como, também, para a compreensão crítica da realidade e do mercado de trabalho. 
O foco dos Institutos Federais será a justiça social, a equidade, a competitividade econômica e a geração de novas tecnologias. Responderão, de forma ágil e eficaz, às demandas crescentes por formação profissional, por difusão de conhecimentos científicos e tecnológicos e de suporte aos arranjos produtivos locais (Brasil, 2009, p.5).

Em oposição ao pensamento vigente durante a sua criação, a Educação Profissional e Tecnológica - ofertada, em especial, nos Institutos Federais e direcionada ao Ensino Médio nos dias atuais - deixa de ser fundamentada apenas nas instruções de trabalho para classes mais pobres e passa a ser vista como possível instrumento de transformação social. Ao possibilitar o ensino associando trabalho, ciência e cultura, estes cursos conferem formação integral ao estudante, objetivando o "permanente desenvolvimento de aptidões para a vida produtiva" (LDB, artigo 39) e a capacidade de adaptar-se, com flexibilidade, ativamente, “às novas condições de ocupação e aperfeiçoamentos posteriores" (LDB, artigo 35). Tem-se, então, como objetivo, o fomento da autonomia intelectual do trabalhador, possibilitando a articulação e a mobilização de competências envolvendo conhecimentos, habilidades, atitudes e valores com o intuito de, na vida prática, oferecer soluções inovadoras e criativas ao mercado profissional e tecnológico.

\subsection{A Educação Profissional e Tecnológica sob a perspectiva de Paulo Freire}

Principal representante do movimento da pedagogia crítica no Brasil, o pedagogo e educador brasileiro Paulo Freire (1921-1997) abordou as relações de poder, desigualdade econômica e opressão, com o objetivo de desenvolver a compreensão crítica da realidade por parte dos alunos e, assim, estimular a tomada de consciência frente à possibilidade de transformação social. Nesse sentido, em "Política e Educação", Freire parte da concepção de que a educação é um ato político, sugerindo que ela é capaz de transformar a realidade.

Não há, finalmente, educação neutra nem qualidade por que lutar no sentido de reorientar a educação que não implique uma opção política e demande uma decisão, também política de materializá-la (Freire, 2001, p.24).

Para efetivar o caráter político da educação, na obra "Pedagogia do Oprimido", Freire se opõe à perspectiva bancária de ensino, no qual o educador "deposita" conhecimento e valores sobre o aluno de forma mecanicista. Nesse momento, segundo Freire,

Educador e educando se arquivam na medida em que, nesta distorcida visão da educação, não há criatividade, não há transformação, não há saber. Só existe saber na invenção, na reinvenção, na busca inquieta, impaciente, permanente, que os homens fazem no mundo, com o mundo e com os outros. Busca esperançosa também (Freire, 1987, p. 38).

Sob tal ótica, essa concepção bancária de educação pode ser observada nas instituições de ensino que aplicam a teoria tradicional de currículo, teorizada por John Franklin Bobbitt (1876-1956), a qual, almejando a eficiência e a produtividade, é centrada na figura do professor. O educador, enquanto detentor do conhecimento, transfere-o para o aluno, o qual, por sua vez, deve armazenar essas informações, de forma memorizada e mecanicista. Sendo assim, não se torna possível a tomada de consciência crítica, voltada para inquietude, autonomia e para o reconhecimento de que a realidade e a estrutura social são mutáveis e são passíveis de serem transformadas.

Quanto mais se exercitem os educandos no arquivamento dos depósitos que lhe são feitos, tanto menos desenvolverão em si a consciência crítica de que resultaria a sua inserção no mundo, como transformadores dele. Como sujeitos (Freire, 1987, p.39).

Para Paulo Freire, a educação deve superar essa perspectiva "bancária" e se tornar emancipadora, isto é, deve ser capaz de estimular o jovem a se libertar da opressão e a tomar consciência do protagonismo do ser humano enquanto "sujeito" na 
história. Essa concepção crítica da teoria curricular pode ser aplicada no contexto de criação dos Institutos Federais, que, segundo Eliézer Pacheco,

Assim, derrubar as barreiras entre o ensino técnico e científico, articulando trabalho, ciência e cultura na perspectiva da emancipação humana é um dos objetivos basilares dos Institutos. Sua orientação deve recusar o conhecimento exclusivamente enciclopédico, assentando-se no pensamento analítico, buscando uma formação profissional mais abrangente e flexível, com menos ênfase na formação para ofícios e mais na compreensão do mundo do trabalho e em uma participação qualitativamente superior neste. Um profissionalizar-se mais amplo, que abra infinitas possibilidades de reinventar-se no mundo e para o mundo, princípios estes válidos inclusive para as engenharias e licenciaturas (Pacheco, 2011, p.15).

Dessa forma, os Institutos Federais buscam a educação emancipadora ao priorizar a formação cidadã em detrimento unicamente da preparação técnica e mecanicista para o mercado de trabalho. Isso destacado conforme Lei $\mathrm{n}^{\circ} 11.892 / 2008$,

Art. $6^{\circ}$ Os Institutos Federais têm por finalidades e características:

II - Desenvolver a educação profissional e tecnológica como processo educativo e investigativo de geração e adaptação de soluções técnicas e tecnológicas às demandas sociais e peculiaridades regionais (Brasil, 2008, Art.6);

Os Institutos Federais oferecem o tripé ensino, pesquisa e extensão, que, outrora, era reservado somente aos espaços das universidades. Assim, ultrapassam a teoria tradicional de currículo, permitindo o envolvimento do estudante de nível técnico com pesquisa aplicada, o que estimula o desenvolvimento da investigação científica e da capacidade de reflexão crítica da realidade. Tal perspectiva pode ser confirmada em

Art. $6^{\circ}$ Os Institutos Federais têm por finalidades e características:

V - Constituir-se em centro de excelência na oferta do ensino de ciências, em geral, e de ciências aplicadas, em particular, estimulando o desenvolvimento de espírito crítico, voltado à investigação empírica;

VIII - realizar e estimular a pesquisa aplicada, a produção cultural, o empreendedorismo, o cooperativismo e o desenvolvimento científico e tecnológico (Brasil, 2008, Art.6);

Além disso, a perspectiva da extensão reforça o compromisso dos Institutos Federais com a sociedade, pois articulam ações integradas à comunidade que os cerca. Nesse sentido, tais instituições devem explorar as potencialidades da mesorregião na qual estão inseridos, combinado ao oferecimento de uma educação que instigue o aluno, enquanto sujeito, a compreender as peculiaridades da realidade local. Consequentemente, os Institutos Federais devem intervir no entorno, fomentando o desenvolvimento regional, a partir da exploração da vocação produtiva local, da geração de tecnologia e conhecimento e da inserção de trabalhadores críticos e aptos para se adaptarem de acordo com as necessidades socioeconômicas. Esse compromisso pode ser verificado em:

Art. $6^{\circ}$ Os Institutos Federais têm por finalidades e características:

II - Desenvolver a educação profissional e tecnológica como processo educativo e investigativo de geração e adaptação de soluções técnicas e tecnológicas às demandas sociais e peculiaridades regionais;

IV - Orientar sua oferta formativa em benefício da consolidação e fortalecimento dos arranjos produtivos, sociais e culturais locais, identificados com base no mapeamento das potencialidades de desenvolvimento socioeconômico e cultural no âmbito de atuação do Instituto Federal (Brasil, 2008, Art.6). 
Por fim, verifica-se que a instituição da Educação Profissional e Tecnológica ofertada pelos Institutos Federais proporcionou um marco inédito na educação brasileira, assumindo um compromisso mais amplo que unicamente a qualificação voltada para a laboralidade. Nesse contexto, pode ser observada a participação do pedagogo Paulo Freire, que, mesmo após o seu falecimento em 1997, ainda contribui para a formação das diretrizes educacionais do país, recusando a educação bancária em prol da formação de um aluno reflexivo, crítico e apto para se portar como "sujeito" na condução da sua realidade socioeconômica.

\section{Considerações Finais}

A partir do trabalho exposto e das reflexões feitas anteriormente, podemos concluir que, em primeiro lugar, a Educação Profissional e Tecnológica no Brasil teve uma expansão sem precedentes na virada do século XXI, impulsionada, inicialmente, pela difusão dos CEFETs e, em seguida, pela criação dos Institutos Federais.

Uma segunda conclusão que podemos inferir refere-se à necessidade de esse ensino ofertado, em especial, pelos Institutos Federais se adequar às mudanças da estrutura socioeconômica do país e da concepção vigente de trabalho. Nesse sentido, conforme apresentado, a transição da sociedade escravista para a sociedade salarial no Brasil ao longo do século XX proporcionou que o trabalho manual - antes desvalorizado - pudesse ser visto como possibilidade de inserção social. Dessa forma, foi ampliada a busca por instituições que ofertavam a Educação Profissional e Tecnológica, as quais se difundiram amplamente pelo território brasileiro, inicialmente, sob o nome de escolas técnicas federais e, posteriormente, como os CEFETs e Institutos Federais.

Além disso, a instituição da ideologia neoliberal na virada do século XXI foi acompanhada pela mudança do perfil de trabalhador desejado pelas empresas. Nesse momento, o empregado deveria ser capaz de fornecer respostas criativas e inovadoras aos desafios profissionais e tecnológicos enfrentados. Sob essa perspectiva, salienta-se, como terceira conclusão, a implantação dos Institutos Federais, que, amplamente influenciados pela pedagogia crítica desenvolvida por Paulo Freire, ofertaram a Educação Profissional e Tecnológica direcionada à formação transversal do estudante. Nessa modalidade de ensino, a educação torna-se instrumento capaz de promover a emancipação do aluno, desenvolvendo a sua compreensão crítica da realidade e a sua autonomia intelectual.

Em seguida, o salto histórico, proporcionado pela criação dos Institutos Federais em 2008, efetivou a educação em sua perspectiva emancipadora e libertadora, assumindo o compromisso de oferecer o ensino público, gratuito e democrático, voltado para a capacitação não somente técnica do aluno como, também, para a tomada de consciência do estudante do seu papel na realidade enquanto sujeito. Sob esse viés, pontua-se a contribuição dessas instituições na formação cidadã do indivíduo, capaz de intervir na realidade que o cerca e de se adaptar, de forma ativa e inovadora, frente aos desafios de ordem profissional e socioeconômica.

Por fim, observa-se a necessidade de desenvolver estudos que busquem demonstrar a aplicação, de forma prática e concreta, dos fundamentos de Paulo Freire na pesquisa e na extensão realizadas pelos Institutos Federais. Ademais, destaca-se a relevância de se verificar de que forma a trajetória acadêmica e profissional do estudante foi impactada pela proposta inovadora de ensino oferecida pelos Institutos Federais de Educação, Ciência e Tecnologia.

\section{Referências}

Brasil. (1909). Decreto n. ${ }^{\circ}$ 7.566, de 23 de setembro 1909. Republica dos Estados Unidos do Brazil, em execução da lei n. 1606 , de 29 de dezembro de 1906. http://portal.mec.gov.br/setec/arquivos/pdf3/decreto_7566_1909.pdf.

Brasil. (1988). Constituição da República Federativa do Brasil de 1988. Planalto. Brasília. http://www.planalto.gov.br/ccivil_03/constituicao/constituicao.htm.

Brasil. (1994). Lei n. ${ }^{\circ} 8.948$, de 08 de dezembro de 1994. Planalto. Brasília http://www.planalto.gov.br/ccivil_03/leis/L8948.htm. 
Research, Society and Development, v. 10, n. 10, e66101017612, 2021

(CC BY 4.0) | ISSN 2525-3409 | DOI: http://dx.doi.org/10.33448/rsd-v10i10.17612

Brasil. (1996). Lei n.99.394, de 20 de dezembro de 1996. Planalto. Brasília. http://www.planalto.gov.br/ccivil_03/leis/19394.htm.

Brasil. (2008). Lei n. ${ }^{\circ} 11.892$, de 29 de dezembro de 2008. Planalto. Brasília. http://www.planalto.gov.br/ccivil_03/_ato2007-2010/2008/lei/111892.htm.

Brasil, Ministério da Educação. Histórico da Educação Profissional e Tecnológica no Brasil. http://portal.mec.gov.br/publicacoes-para-professores/30000uncategorised/68731-historico-da-educacao-profissional-e-tecnologica-no-brasil.

Brasil, Ministério da Educação. Um novo modelo em Educação Profissional e Tecnológica. http://portal.mec.gov.br/index. php?option=com_docman\&view=download\&alias=6691-if-concepcaoediretrizes\&Itemid=30192.

Freire, P. (1979). Educação e mudança. (12a ed.), Paz e Terra.

Castel, R. (1997). Desigualdade e a Questão Social. EDUC.

Freire, P. (2001). Política e Educação. (5a ed.), Cortez.

Freire, P. (1987). Pedagogia do Oprimido. (17a ed.), Paz e Terra.

Frigotto, G. (2001). Educação e Trabalho: bases para debater a Educação Profissional Emancipadora. Perspectiva, 19, 71-87, https://periodicos.ufsc.br/index.php/perspectiva/article/view/8463/7770.

Lorenzet, D., Andreolla, F., \& Paludo, C. (2020). Educação Profissional E Tecnológica (EPT): os desafios da relação trabalho-educação. Trabalho \& Educação, 29,.15-28, https://periodicos.ufmg.br/index.php/trabedu/article/view/13522/19728.

Ludke, M. \& Andre, M. E. D. A. (1986). Pesquisas em educação: uma abordagem qualitativa. E.P.U.

Kunze, N. C. (2009). O surgimento da rede federal de educação profissional nos primórdios do regime republicano brasileiro. Revista Brasileira de Educação Profissional e Tecnológica. 2, 8-24. http://portaldoprofessor.mec.gov.br/storage/materiais/0000013581.pdf.

Marx, K. (1982). O capital. (7a ed.), Difel.

Pacheco, E. (2011). Os Institutos Federais: uma revolução na educação profissional e tecnológica. Fundação Santillana/ Moderna.

Phillips, B. S. (1974). Pesquisa Social. Agir.

Ramos, M. N. (2014). História e Política da Educação Profissional. Curitiba: Instituto Federal do Paraná. https://curitiba.ifpr.edu.br/wpcontent/uploads/2016/05/Hist\%C3\%B3ria-e-pol\%C3\%ADtica-da-educa\%C3\%A7\%C3\%A3o-profissional.pdf.

Thompson, E. (1981). A miséria da teoria ou um planetário de erros. Jorge Zahar. 